\title{
Wood-Plastic Composite Technology
}

\author{
Douglas J. Gardner ${ }^{1} \cdot$ Yousoo Han ${ }^{1} \cdot$ Lu Wang ${ }^{1}$
}

Published online: 4 June 2015

(C) Springer International Publishing AG 2015

\begin{abstract}
Wood-plastic composites (WPCs) are a form of composite combining wood-based elements with polymers. The processes for manufacturing WPCs include extrusion, injection molding, and compression molding or thermoforming (pressing). Newer manufacturing processes for WPCs include additive manufacturing via fused layer modeling and laser sintering. An important constraint for polymers used in WPCs is requiring process conditions (melt temperature, pressure) that will not thermally degrade the wood filler. Wood degrades around $220^{\circ} \mathrm{C}$; thus, generalpurpose polymers like polyethylene and poly vinyl chloride are typically used for manufacturing WPCs. Wood fibers are inherently hydrophilic because of the hydroxyl groups contained in the cellulose and hemicellulose molecular chains. Thus, modification of the wood fiber via chemical or physical treatments is very critical to making improved WPCs. The most abundant profiles made from wood-plastic composites are boards or lumber used in outdoor decking applications. Although early WPC products were mainly extruded for profiled sections, nowadays, many injected parts made of WPC are being introduced for various industries, including electrical casings, packaging, daily living supplies, and civil engineering applications. Mold and mildew and color fading of
\end{abstract}

This article is part of the Topical Collection on Wood Structure and Function

Douglas J. Gardner

douglasg@maine.edu

Yousoo Han

yousoo.han@maine.edu

Lu Wang

lu.wang@maine.edu

1 Advanced Structures and Composites Center, University of Maine, 35 Flagstaff Road, Orono, ME 04469-5793, USA
WPCs tend to be the durability issues of prime importance for WPCs. Most recent research on WPC durability focuses on studies to better understand the mechanisms contributing to various degradation issues as well as methods to improve durability. Most WPC products in the USA are utilized in building materials with few exceptions for residential and commercial building applications, which means that building codes are the most important national rules for the WPC manufacturers. New developments are being made especially in the area of nano additives for WPCs including nanocellulose. Recently, the trend of patent registrations for WPCs has shifted to new products or applications instead of the materials itself.

Keywords Additive manufacturing - Fused layer modeling · Cellulose nanofibrils $\cdot$ Adhesion strength $\cdot$ Composite

\section{Introduction}

A wood-plastic composite (WPC) is a common term referring to wood-based elements such as lumber, veneer, fibers, or particles that are combined with polymers to create a composite material. It is a broadly used term, and as such, wood elements can be combined with either thermosetting or thermoplastic polymers. The term wood-plastic composite is used interchangeably with wood-polymer composites, and the wood composites made from either thermoplastic or thermosetting polymers are often categorized as separate material types [1]. Examples of wood-plastic composites made from different polymer types and wood elements are listed in Table 1.

The earliest wood-plastic composites appeared nearly a century ago where wood flour was combined with phenolformaldehyde resin to create a composite material used as an 
Table 1 Wood-plastic composites (WPCs) are materials comprising polymers and wood elements

\begin{tabular}{lll}
\hline Polymer type & Wood elements & WPC types \\
\hline Thermoplastic polymers & Lumber, veneer, fibers, particles, flour, etc. & Extruded lumber, injection-molded automotive components \\
Thermosetting polymers & Lumber, veneer & Polymer impregnated wood (impreg, compreg) \\
\hline
\end{tabular}

automobile gearshift knob [2]. An excellent overview of composites made by combining wood with thermosetting polymers was provided by Rowell and Konkol [3]. An early reference to combining wood sawdust with thermoplastic resin via extrusion processing appeared more than 60 years ago [4]. More recent references on wood-plastic composites from thermoplastic polymers include Oksman et al. [5] and Klyosov [6]. Also of interest is the production of eco-composites utilizing bio-derived polymer matrices [7]. This review will focus on wood-plastic composites manufactured from thermoplastic polymers and wood flour or wood fibers.

\section{Manufacturing Processes}

The primary manufacturing processes for wood-plastic composites are extrusion, injection molding, and compression molding or thermoforming (pressing). Newer manufacturing processes for WPCs include additive manufacturing via fused layer modeling and laser sintering [8-11].

\section{Extrusion Processing}

The extruder is the core of a WPC profile processing system, and the primary purpose of the extruder is to melt the polymer and mix the polymer, wood, and additives in a process referred to as compounding. In addition, the extruder conveys the compounded wood-polymer mixture through the die. There are four primary types of extrusion systems used to process WPC profiles. These are the (1) single screw, (2) co-rotating twin screw, (3) counter-rotating twin screw, and (4) Woodtruder ${ }^{\mathrm{TM}}$.

\section{Single-Screw Extruder}

A single-screw fiber composite extruder is the simplest extrusion system for producing WPC profiles. A typical singlescrew extruder will have a barrel length to diameter $(L / D)$ ratio of 34:1. It will employ two stages, melting and metering, and a vent section to remove volatiles. The material form for the single-screw extruder will be pre-compounded fiber-filled polymer pellets. A dryer may also be required to dry the pellets. The material feed method is usually by gravity hopper. The melting/mixing mechanism is barrel heat and screw shear. Advantages of the single-screw extruder are that it is a proven technology and this method has the lowest capital acquisition cost. Disadvantages include high raw material cost, lower output rates, drying system required, polymer is melted with the fiber with greater risk of fiber thermal decomposition, high screw speed (rpm) with greater risk of burning at the screw tip, and inability to keep melt temperature low with higher head pressures.

\section{Counter-Rotating Twin-Screw Extrusion}

Counter-rotating twin-screw extruders excel in applications where heat-sensitive polymers like rigid polyvinyl chloride (PVC) are utilized, low temperature extrusion for fibers and foams, non-compounded materials like powder blends, materials that are difficult to feed, and those materials that require degassing. The counter-rotating twin screw can either have parallel or conical screw configurations. The fiber/flour and polymer are in the same polymer size, usually 250 to $400 \mu \mathrm{m}$. Material preparation includes fiber drying followed by highintensity blending with the polymer and additives. The material feed method usually utilizes a crammer feeder. The melting/mixing mechanism is barrel heat and screw mixing. Screw mixing is accomplished through screw flight cut-outs and gear mixers. Moisture removal is through vacuum venting. Advantages of counter-rotating twin-screw extrusion include its low screw speed (rpm) and low shear mixing, and it is a proven technology. Disadvantages include that a drying system is required, a size reduction system for fed materials may be necessary, a pre-blending system is required, and material transportation can impact the mix feed ratios.

\section{Co-rotating Twin-Screw and Hot Melt Single-Screw Wood Composite System}

A co-rotating twin screw in combination with a hot melt single screw can be used to produce wood-plastic composite profiles. In this case, a parallel 40:1 $L / D$ co-rotating twin-screw extruder is coupled with a hot melt 10:1 L/D, single-screw extruder. The material for this system is wood flour or fiber at ambient moisture content ( 5 to $8 \%$ ), and the polymer and additives can be in their natural states. No material preparation is required in terms of pre-blending components. The preferred material feed systems are gravimetric feeders and twin-screw side feeders. The melting/mixing mechanism includes barrel heat, screw speed (rpm), and screw mixing. Moisture removal is accomplished through the use of atmospheric and vacuum vents. Advantages of this system include the ability to process wood at ambient moisture content since 
the extruder is used to dry the fiber with the elimination of drying and pre-blending operations, and good fiber/polymer mixing. Disadvantages include the need for peripheral feeding systems, high screw speed (rpm) and no screw cooling (greater risk of burning), inability to keep melt temperature low with higher head pressures, and polymer is still melted with the fiber (greater risk of burning, more difficult to vent).

\section{Woodtruder ${ }^{\mathrm{TM}}$}

The Woodtruder ${ }^{\mathrm{TM}}$ includes a parallel 28:1 $L / D$ counterrotating twin- and a $75-\mathrm{mm}$ single-screw extruder, a blending unit, a computerized blender-control system, a die tooling system, a spray cooling tank with driven rollers, a traveling cutoff saw, and a run-off table. As processing begins, ambient moisture content wood flour is placed into the unit's fiber feeder and dried within the twin screw. Meanwhile, separate from the fiber, the plastics are melted. The melting/mixing mechanism includes barrel heat and screw mixing. The separation of wood conveying and plastic melting ensures that fibers will not be burned during plastic melting and that the melted plastic will encapsulate the fibers completely. These materials are then mixed, and any remaining moisture or volatiles are removed by vacuum venting. Advantages of this system include that the flour and additives are in their natural states and no material preparation is required. Gravimetric feeders are preferred as the material feed method. Advantages of the Woodtruder ${ }^{\mathrm{TM}}$ include the ability to process fiber at ambient moisture content ( 5 to $8 \%$ ), separate melting process of the polymer, good polymer/fiber mixing, screw cooling is included on the twin screw, the ability to maintain a low melt temperature with a high head pressure, superior venting, the elimination of drying, size reduction and separate preblending equipment, highly flexible integrated process control system for material feeding, and extruder unit operations. Disadvantages include lower product throughput, higher capital costs, and using the main extruder as a dryer is not the most efficient manner to process dry wood flour.

\section{Miscellaneous Post-extruder Unit Operations}

Along with the extruder, the die is an important part of the WPC profile extrusion system. The die dictates the dimensions and profile (shape) of the extruded part. The die is typically heated using band or cartridge heating elements and may employ air-cooling to adequately process hollow profile parts. Dies can be quite simple or complex depending on the desired profile. After the die, comes the cooling tank, which is used to freeze the extruded profile in its linear shape. The cooling tank consists of a conveyer system with water spray heads that spray cool water on the profile extrudate. The cooling tank may be 6 to $12 \mathrm{~m}$ long depending on the extruder material output and the cooling capacity required. The water spray is typically recycled and may go through a chiller or heat exchanger to keep the spray water cool. After the cooling tank, the WPC profile goes through a cut-off saw that can cut the lumber to the desired lengths.

\section{Injection Molding}

Injection molding of wood-plastic composites is used to produce parts containing complex geometries and also requiring no finishing step. A typical example of a WPC injection molded part is a post cap for guard rail structures. Research specifically targeting the injection molding process for WPCs is limited compared to extrusion processing, but topics tend to be similar and focus on material compositions and properties [12]. There have also been reports examining injection molding (IM) to produce WPC microcellular foams $[13,14]$ as well as IM of WPC made with biopolymers [15].

\section{Compression Molding or Thermoforming}

Compression molding or thermoforming of wood-plastic composites has been researched for many years and has been used extensively in the manufacture of automobile composite parts [16]. The use of continuous belt presses for producing WPC panels and glass-reinforced WPC panels has also been demonstrated $[17,18]$. TechnoPartner Samtronic GmbH, Goppingen, Germany can produce continuous WPC sheets up to $1.3 \mathrm{~m}$ wide and $13 \mathrm{~mm}$ thick on a continuous basis.

\section{Material Advances}

\section{Novel Polymer Matrices}

An important constraint for polymers used in WPCs is requiring process conditions (melt temperature, pressure) that will not thermally degrade the wood filler. Wood degrades around $220^{\circ} \mathrm{C}$; thus, general-purpose polymers are typically used for manufacturing WPCs. Extensive WPC research has focused on polyethylene (PE) [19], polypropylene (PP) [20], polyvinyl chloride (PVC) [21], polystyrene (PS) [22], and poly methyl methacrylate (PMMA) [23]. The mechanical properties of these polymers can be enhanced by the addition of wood fibers, but the resulting composites do not have mechanical properties expected for most engineering applications. As the understanding of biocomposite manufacturing expands, engineering plastics are also being explored in WPC applications.

Nylon 66 was studied as a matrix for WPCs for potential under-the-hood applications [24]. Results of the study showed improved storage modulus, thermal stability, and reduced glass transition temperature for the wood-nylon WPC compared to the pure nylon 66. In some instances, engineering plastics are incorporated into general-purpose plastics to form 
polymer blends. Lei and $\mathrm{Wu}$ applied a two-step extrusion process to make the blends of polyethylene terephthalate (PET)/high-density polyethylene (HDPE) and added wood flour into the blends [25]. Because the temperature for the second extrusion was only used for melting the HDPE, the wood flour did not thermally degrade. Wood flour was reported to increase the PET/HDPE blend mechanical properties, storage modulus, and matrix crystallinity. Ultra-highmolecular-weight polyethylene (UHMWPE)/wood flour composites were prepared by compression molding [26], and improvements were found in tensile modulus, flexural modulus, shear modulus, and hardness. Chotirat et al. reported that wood sawdust increases the modulus of acrylonitrile-butadiene-styrene (ABS) [27]. However, wood flour decreased the strength of the composite attributable to weak interfacial bonding.

Styrene maleic anhydride (SMA) copolymers are used in the automobile industry for interior components. Adding wood fibers into SMA benefits the recyclability and mechanical properties. Simonsen et al. found that wood fillers improved the stiffness and strength of SMA, while it decreased the notched Izod impact strength [28]. Also, the glass transition temperature decreased for filled SMA, a phenomenon that stimulated the authors to question whether chemical bonding occurred between the wood flour and matrix. Other research on wood/SMA composites is to use the water generated from esterification reaction between wood fibers and SMA matrix as a foaming agent [29•]. The resulting SMA WPCs from a pilot-scale extrusion process reduced the resulting composite density up to $30 \%$ and increased its flexural strength and stiffness to a level higher than nylon 66 .

Biodegradable polymer matrices continuously attract research attention. Gregorova et al. made wood fiber/poly lactic acid (PLA) composites by solution casting with subsequent hot pressing [30]. The addition of wood fiber increased the glass transition temperature, Young's modulus, and storage modulus of pure PLA, while the tensile strength and elongation at break decreased. Another way to process wood/PLA composites is by extrusion. Wood/PLA compounds at different wood fiber loading levels were studied by [31]. Composite strength was not improved by the addition of wood fiber, but flexural and storage moduli were greatly enhanced. Lee and Ohkita studied the mechanical and thermal flow properties of wood flour/polycaprolactone (PCL) and wood flour/ polybutylene succinate-butylene carbonate (PBSC) composites made by hot pressing [32]. The stiffness of the PCL was significantly increased by adding wood flour. However, both the elongation to break and tensile strength were decreased for PCL and PBSC. Poly(3-hydroxybutyrate) (PHB) was used as a matrix for WPC, and its biodegradability was assessed [33]. The results obtained showed that wood/PHB composites can be biodegraded, and the decay rate increased with an increase in wood loading level. Singh and Mohanty investigated WPCs from wood fibers and polyhydroxybutyrateco-valerate (PHBV) by extrusion processing [34]. They found that tensile, flexural, and storage moduli of PHBV were increased by the addition of wood fibers. On the contrary, the coefficient of linear thermal expansion and notch impact strength decreased.

\section{Wood Modification}

Wood fibers are hydrophilic because of the hydroxyl groups contained in the cellulose and hemicellulose molecular chains. However, most thermoplastics employed in WPCs are hydrophobic. Wood fibers will agglomerate during compounding attributed to hydrogen bonding. As a result, the wood may not be well dispersed in polymer matrices, and therefore, its reinforcing effect can be compromised. The mechanical properties of plastics can be degraded in some instances when aggregation occurs. Thus, modification of the wood fiber is very critical to making improved WPCs.

\section{Thermal Treatment}

Thermal treatment of wood refers to a process where wood fibers are conditioned with heat and moisture at a temperature around $230^{\circ} \mathrm{C}$ to produce an inert surface and eliminate hemicellulose [35]. Andrusyk et al. produced WPCs using extracted wood flour and polypropylene [36]. The mechanical properties of the composite were enhanced significantly. Flame spread, specific gravity, and thermal expansion remained the same after the treatment. Similar results were found in Hosseinaei's research where southern yellow pine was hot water extracted at three temperature levels and made into WPCs with polypropylene [37]. Tensile strength and thermal stability were found to be increased by the extraction process. Water absorption and thickness swelling of the composites made by PP or HDPE and pine (Pinus ponderosa) were reduced after hot water extraction [38].

\section{Energetic Treatment}

Atmospheric glow discharge (AGD) was a technique using high-voltage radio frequency with industrial plasma. The advantage of AGD is it can treat the surface with gases at atmospheric pressure. Wood flour was treated with AGD where the surrounding gas was hexamethyl disiloxane [39]. The treated wood flour dispersed evenly in the PP and had better interfacial bonding with the matrix. Corona treatment was conducted on both wood fibers and PE matrix to improve interfacial bonding [40]. As a result, a significant increase in strength properties and ductility of the composite was observed. 


\section{Chemical Treatment}

Besides modifying the hydrophobicity of wood fibers, chemical treatments can add functional moieties to wood fibers by reactions with their surface functional groups [41]. The modified wood surface will have improved interfacial bonding with polymer matrices. Coupling agents are chemicals that have two different functional end groups. One group is used to react with the hydroxyl group of the wood fiber while the other is used to interact with polymer matrix. More than 40 types of coupling agents have been investigated to modify wood fibers, and the most popular ones are isocyanates, anhydrides, silanes, and anhydride-modified copolymers [42]. Two maleic anhydride grafted polypropylene (MAPP) copolymers of different molecular weights were used to treat wood flour to make composites with PP. The PP-wood composites attained the highest tensile strength as the ratio between MAPP and wood flour was 0.05-0.1. MAPP with a larger molecular weight contributed more to the composite strength improvement. MAPP with a smaller molecular weight improved processability significantly [43]. Vinyltrimethoxy silane at different concentration levels was added during the compounding process by a twin-screw extruder [44]. The resulting wood/HDPE composite had increased toughness, impact strength, and creep properties, while the flexural modulus was lower. Those changes resulted from the fact that the polymer matrix in the silane-treated WPC exhibited lower crystallinity. The benefits and drawbacks of various treatments on wood flour on the properties of wood/PP composites were compared [45]. Benzylation was found to decrease the water absorption of WPC but inversely affected the interfacial adhesion. Two surfactants (stearic acid and cellulose palmitate) did not improve the tensile strength of WPC, but they were beneficial to the homogeneity and processability of the composites. Alkaline treatment was found to improve the dispersion of wood flour in PP. The treatment slightly increased the mechanical properties [46]. Acetylation of the wood was applied to improve the incompatibility between wood fiber and HDPE [47]. This treatment improved interfacial adhesion and tensile modulus, whereas the strain at failure decreased. Esterification (acetate, propionate, benzoate) was used to treat poplar wood fibers [48]. The resulting wood fiber/HDPE composites had better mechanical properties, improved resistance to fungi, and enhanced weathering performance.

\section{Additives}

Additives are fairly important ingredients of WPCs that can be used for various purposes. The types of additives used in the WPC industry include lubricants and rheology control additives, coupling agents, stabilizers, fillers, density reduction additives, biocides, product aesthetics additives, flame retardants, and smoke suppressants. The effects of lubricant content on processing and property of wood flour/ HDPE composites were explored [49]. They found the apparent viscosity decreased by increasing the lubricant content. An optimal amount of wood fiber, HDPE, maleic anhydride polyethylene (MAPE), and lubricant can facilitate the processing by reducing viscosity and maintaining the mechanical properties and surface smoothness. Li and Wolcott studied the rheology of HDPE/maple composites after adding two distinct lubricants into the system: an ester and a zinc stearate [50]. The ester-type lubricant enhanced the dispersion of maple particles and provided good external lubrication.

Biocides were employed to treat WPCs and their performance was evaluated [51]. The weight loss of the wood component in the WPCs caused by brown rot fungus was less compared to solid wood. The reduced decay of the wood is attributed to the plastic encapsulation effect. $\mathrm{Na} / \mathrm{Ca}$ borate performed marginally better than zinc borate. Similarly, Dawson-Andoh and Matuana used two types of biocides (silver and zinc) at three concentrations to treat WPCs made from wood flour and HDPE [52]. Overall, the zinc biocide controlled the fungal growth and discoloration effectively and it attained the best effect at $1 \%(w / w)$ loading level. In contrast, the silver biocide did not inhibit the fungi or discoloration, which was deemed as inefficient for their study.

Ultraviolet (UV) light will cause WPCs to discolor and lose mechanical strength gradually. To overcome this durability issue, stabilizers like hindered amine light stabilizers (HALS) and ultraviolet absorbers (UVA) were applied to WPCs [53]. Diester HALS can stabilize the color of WPC by scavenging the free radicals generated by UV exposure. The higher the molecular weight of the diesters, the better stability it had in the composite. When combining benzotriazole UVA and diester HALS together, they reduced the discoloration of the composite synergistically. Chaochanchaikul and Sombatsompop investigated three different UV stabilizers for wood/PVC composites [54]. They found that UV stabilizers reduced the photodegradation of the WPC, however, did not appear to affect the mechanical properties. The same authors also studied the influences of thermal stabilizers on the structural and thermal properties of wood/PVC composites [55]. Results showed that wood flour accelerated the thermal degradation of PVC, and this can be improved by adding metal stearates and organotin. Methyl tin mercaptide was proven to improve the thermal stability for wood/PVC composites in their study.

Instead of using MAPE, a compatibilizer system consisting of a paper wet-strength agent polyaminoamide-epichlorohydrin (PAE) and stearic anhydride was investigated for wood/PE composites [56]. Results indicated that the system increased the modulus of rupture (MOR) by $33 \%$ and modulus of elasticity (MOE) by $40 \%$ compared to pure wood/PE 
composites. Also, the additive system performed better in MOE though a slightly lower MOR was obtained compared to the composites treated with MAPE. The same authors studied another system made by polydiphenylmethane diisocyanate (PMDI) and stearic anhydride for wood/PE composites [57]. The MOR and MOE of the composites were both significantly higher than MAPE treated ones. The improved MOR and MOE arise from the improved interfacial adhesion and enhanced wood particles.

Foamed WPCs have favorable properties like reduced weight and cost, increased impact strength, strength-toweight ratio, and surface definition (sharper contours and corners) [58]. Three types of chemical foaming agents (endothermic, exothermic, and endothermic/exothermic) were added to mixed wood fiber and PP granules and then injection molded [59]. Considering cell size, diameter, and distance for the micro foamed composites, exothermic foaming agents were the best ones to produce foaming in a PP matrix. Density of the WPCs was reduced by nearly $30 \%$, and there was up to a $70 \%$ decrease in surface roughness. Zhang et al. developed a tandem extrusion system for making microcellular WPCs by using $\mathrm{CO}_{2}$ as a physical blowing agent [60]. It was reported that the tandem extrusion system can produce WPCs with fine-cell structure that exhibit improved cell morphology. Another study investigated the microcellular WPCs from injection, extrusion, and compression molding processes for interior automobile composites where injection molding was found to be the best manufacturing method in terms of cell morphology, density reduction, odor emissions, and mechanical properties [61].

Fire performance of WPCs is quite important if they are designed for furniture and residential building applications. To better understand the behavior of fire retardants on the fire performance of wood flour/PE composites, five fire retardant systems (decabromodiphenyl oxide, magnesium hydroxide, zinc borate, melamine phosphate, and ammonium polyphosphate) were investigated [62•]. All the five reagents improved the fire performance of WPCs. Interestingly, adding wood flour alone can dramatically ameliorate the fire performance too.

Toughening agents were explored to improve the reduced impact strength caused by adding wood fibers into polymer matrices. PHA was found to increase the impact strength of wood/PLA composites but compromised tensile strength and thermal stability [63]. Styrene-butadiene-styrene (SBS) block copolymer can also improve the impact resistance and elongation at the break at the expense of tensile strength [64•]. No significant effect on thermal stability of WPCs was caused by this toughening agent. Plasticizer was investigated in WPCs as well. It can reduce the increased glass transition temperature $\left(T_{\mathrm{g}}\right)$ caused by adding wood flour into polymer matrix thus facilitates the manufacturing [65]. Wood flour/
LDPE composites had reduced viscosity and less extrusion torque during processing. It displayed better elongation property when plasticizers were applied [66].

\section{Profiles or Parts}

The commercial profiles made of wood-plastic composites are plank-type boards for decking, fencing, and siding in building/construction industry, molded sheets in the automobile industry, trimming/framing parts in the furniture industry, injected parts in the electrical industry, sheet piles of sea retaining walls in the civil engineering industry, and a variety of injected molded parts for toys, musical instruments, etc. The various profiles are demonstrated in Figs. 1 and 2.

The most abundant profiles made from wood-plastic composites are boards or lumber used in outdoor decking applications. Decking boards are available in the markets in a wide variety of forms including solid, foamed, channeled, capstocked, or coated sections.

Although early WPC products were mainly extruded for profiled sections, nowadays, many injected parts made of WPC have been introduced for various industries, including electrical casings, packaging, daily living supplies, and civil engineering applications since 2010.

Technical issues in the shaping of WPCs are extrusion die design for thin profile walls, running channel design for complicated structures in injection molding, and smooth WPC melt running during processing to prevent plug-in problems or thermal degradation of the melts. Additionally, the formulation must be customized for each different processing method and target application.

\section{Durability}

Good overviews covering various aspects of WPC durability can be found in Stark and Gardner [67], Klyosov [6], and Morrell et al. [68]. The durability of wood-plastic composites falls under two broad categories: structural durability and aesthetic durability. Examples of WPC durability categories and material properties impacted are listed in Table 2. Structural durability is most important from a safety standpoint for building structures made using WPCs, but aesthetic durability can be as important to consumers and problems as WPC appearance have led to a number of class action law suits for WPC decking in particular [69]. Mold and mildew and color fading of WPCs tend to be the durability issues that factor in the promulgation of class action law suits.

Most recent research on WPC durability focuses on studies to better understand the mechanisms contributing to various degradation issues as well as methods to improve durability. 


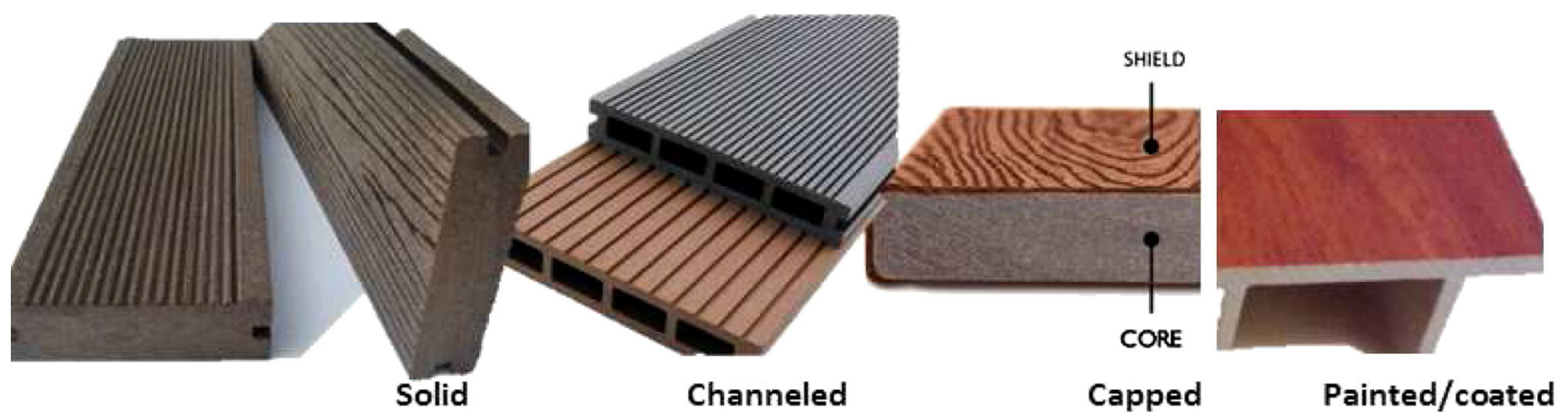

Fig. 1 WPC decking boards with different shapes

\section{Decay Studies}

Ashori et al. [70] examined the effects of chemical preservative treatments in WPCs. The fungicide-treated WPCs were shown to be more resistant to decay than the untreated samples. Shirp and Wolcott [71] investigated the influence of fungal decay on the physical and mechanical properties of WPCs. They reported that WPCs can be designed to provide good fungal durability by controlling the ratio of wood to plastic in the composite formulation. Fabiyi and McDonald [72] studied the effect of wood species on property and weathering performance of WPCs. Among a number of wood species studied, hybrid poplar and ponderosa pine which are light-colored woods exhibited better color stability. Fabiyi et al. [73] also looked at the biodegradation of different species of WPC and Douglas-fir (Pseudotsuga menziesii) was found to be less susceptible to white rot. Kim et al. [74] studied the effect of wood species on water sorption and durability of wood-plastic composites. They reported that the use of durable wood species in WPCs resulted in improved durability performance.

\section{Weathering Studies}

Weathered WPC surfaces have been characterized via infrared and X-ray photoelectron spectroscopy and contact angle analysis [75]. It was reported that the surface analysis techniques should be used together to develop a full understanding of the changes that occur on WPC surfaces exposed to weathering.
Fabiyi et al. [76] reported on the visual appearance and chemical changes in weathered WPCs. It was determined that oxidation and degradation of lignin influenced WPC color changes during weathering. Co-extruding an opaque coating on WPCs was shown to improve the resistance to color changes of weathered WPCs [77]. Thermal treatment of wood has been shown to improve the dimensional stability of WPC panels [78]. Segerholm et al. [79] studied water absorption in artificially aged wood-plastic composites. The artificial weathering caused polymer matrix cracking and wood-matrix debonding contributing to increased moisture uptake in the WPCs.

\section{Fire Retardancy Studies}

Garcia et al. [80] reported on WPCs with improved fire retardancy and durability performance through the addition of a combination of fire retardants and light stabilizers. Stark et al. [81] evaluated various fire retardants in polyethylene matrix WPCs. It was determined that magnesium hydroxide and ammonium polyphosphate improved the fire performance of the WPCs.

\section{Product Standards}

In the USA, construction products are ruled by building codes that specifies the minimum acceptable levels of safety for constructed objects. Most WPC products in the USA are utilized in
Fig. 2 Photos of various WPC profiles for different applications (Photos by the courtesy of JERUWERK GmbH \& Co., Germany)

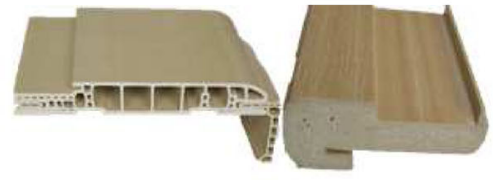

Frames/trims

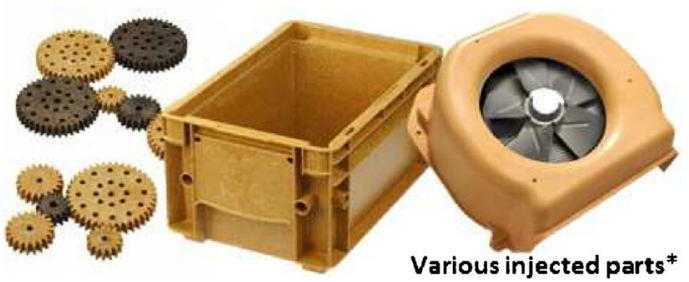

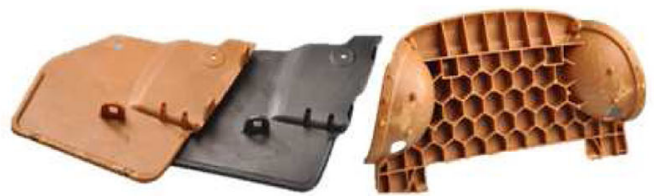

Parts in automobiles*

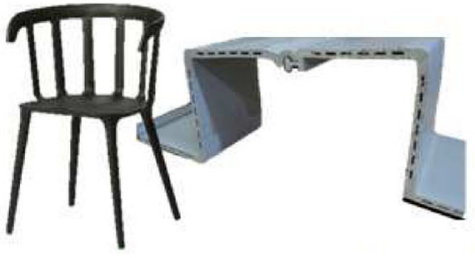

Ikea WPC chair UMaine WPC seawall 
Table 2 Categories of wood-plastic composite durability and material properties impacted

\begin{tabular}{ll}
\hline Durability category & Material properties impacted \\
\hline Structural & $\begin{array}{c}\text { Mechanical properties (strength and stiffness, thermal (fire), creep) physical properties (swelling, shrinkage, warping), } \\
\text { biological degradation (decay) } \\
\text { Weathering (color fading), biological attack (mold, mildew), food stains }\end{array}$ \\
Aesthetic & Werions \\
\hline
\end{tabular}

building materials with few exceptions for residential and commercial building applications, which means that building codes are the most important national rules for the WPC manufacturers. The International Code Council (ICC) has historically developed a major model building code. In the past, WPC and plastic composites have not been addressed directly in the building code. However, as of 2009, the International Residential Code (IRC) added WPCs to the code. The most notable agencies for the compliance evaluation are ICC-ES (International Code Council-Evaluation Service), Architectural Testing, Inc., and Underwriters Laboratory. If a product complies with code requirements, the agencies publish a report to that effect. Each agency issues different types of reports, such as Evaluation Service Report (ESR) by ICC, Code Compliance Research Report (CCRR) by Architectural Testing, Inc., and UL Listing by Underwriters Laboratory (Table 3).

Two important acceptance criteria in the building code are AC109: Acceptance criteria for thermoplastic composite lumber products and AC 174: Acceptance criteria for decking and railing products. Under these criteria, materials are evaluated for their stiffness, strength, and ability to withstand environmental factors such as termite damage, decay, and fire performance. Related material testing standards for WPCs are listed below.

As a benefit of the certifications, the building contractors and material suppliers can expect product reliability and appropriate quality controls from WPC manufacturers. Also, certification has a paper trail that enables it to be traced from the job site to the raw materials.

\section{New Developments}

\section{Cellulose Nanocomposites}

The definition of a nanocomposite is a multiphase solid material where one of the phases has one, two, or three dimensions in the nanometer scale that is of less than $100 \mathrm{~nm}$ [82]. Therefore, cellulose nanocomposites refer to those whose reinforcements are cellulose nanoparticles. Cellulose nanoparticles fall into two categories depending on the production methods. One is cellulose nanocrystals (CNCs). Pulp fiber is treated by acid to remove the amorphous areas via breaking the linkages between cellulose and hemicellulose, thus releasing the crystalline cellulose fiber [83]. The other type of cellulose nanoparticle is cellulose nanofibrils (CNFs). The method to produce CNF applies a shear force on pulp fibers perpendicular to its axis to break the inner bonding of nanofibers [84]. For this reason, both crystalline and amorphous areas are contained in CNFs.

Because cellulose nanoparticles have extraordinary properties, they are often incorporated into polymer matrices as reinforcements or functional additives. Cellulose nanocrystals

Table 3 Related material testing standards for building code acceptance criteria AC 109 and 174

\begin{tabular}{|c|c|}
\hline Designation & Name \\
\hline ASTM D7031 & Standard Guide for Evaluating Mechanical and Physical Properties of Wood-Plastic Composite Products \\
\hline ASTM D7032 & $\begin{array}{l}\text { Standard Specification for Establishing Performance Ratings for Wood-Plastic Composite Deck Boards and Guardrail Systems } \\
\text { (Guards or Handrails) }\end{array}$ \\
\hline ASTM D1413 & Test Method for Wood Preservatives by Laboratory Soil-block Cultures \\
\hline ASTM G154 & Standard Practice for Operating Fluorescent Light Apparatus for UV Exposure of Nonmetallic Materials \\
\hline ASTM D2565 & Practice for Operating Xenon Arc-type Light-exposure Apparatus With or Without Water for Exposure of Plastics \\
\hline ASTM D2915 & Practice for Evaluating Allowable Properties for Grades of Structural Lumber \\
\hline ASTM D2990 & Test Methods for Tensile, Compressive, and Flexural Creep and Creep-rupture of Plastics \\
\hline ASTM D3345 & Test Method for Laboratory Evaluation of Wood and Other Cellulosic Materials for Resistance to Termites \\
\hline ASTM D5456 & Specification for Evaluation of Structural Composite Lumber Products \\
\hline ASTM E499 & Practices for Force Verification of Testing Machines \\
\hline ASTM E84 & Test Methods for Surface Burning Characteristics of Building Materials \\
\hline ASTM D6109 & Standard Test Methods for Flexural Properties of Unreinforced and Reinforced Plastic Lumber \\
\hline ASTM D1761,(1) & Test Methods for Mechanical Fasteners in Wood, American Society for Testing and Materials \\
\hline
\end{tabular}


have been studied less as the reinforcement for polymers compared to CNFs because the projected costs to produce CNCs commercially are significantly larger than the process to produce CNFs. Also, CNFs are a better candidate as the reinforcement than CNCs because CNFs have a larger aspect ratio and fiber entanglement in the composite [84]. Another reason may be that thermal stability of CNCs was impaired by the acid hydrolysis, which becomes a serious problem during manufacturing such as extrusion [82].

Various thermoplastic and thermosetting polymer matrices have been investigated for CNFs, and their enhancements on properties were reported. Malainine et al. made nanocomposites by adding CNFs into poly(styrene-co-butyl acrylate) latex at different loading levels and solution casting [85]. The tensile strength of the polymer was increased to $34.5 \mathrm{MPa}$ at $10 \mathrm{wt} \% \mathrm{CNFs}$ compared to $0.552 \mathrm{MPa}$ with no CNFs. The stress at break increased from 7.1 to 14.5 MPa. Leitner et al. made CNFs/polyvinyl alcohol (PVOH) composites by solution casting [86]. Mechanical properties of $\mathrm{PVOH}$ increased with an increase in filler content. At a filler content of $50 \mathrm{wt} \%$, the elastic modulus of $\mathrm{PVOH}$ was 20 -fold and tensile strength was 3.5 times higher than pure PVOH. CNFs/starch composites were produced by solution casting [87]. With $10 \mathrm{wt} \%$ of CNFs, starch had a modulus of $271 \mathrm{MPa}$ improved from $111 \mathrm{MPa}$. The glass transition of reinforced starch was higher than pure starch. Peng et al. made CNFs/PP nanocomposite through melt compounding and extrusion with maleic anhydride polypropylene as the coupling agent [88]. Increases of $36 \%$ in tensile modulus, $21 \%$ in flexural modulus, and $23 \%$ in impact strength were observed for reinforced PP at a fiber content of $6 \mathrm{wt} \%$. CNF-reinforced PLA was developed using twin-screw extrusion at various fiber loadings [89]. At a fiber loading of $5 \mathrm{wt} \%$, tensile modulus and strength were improved by 25 and $23 \%$, respectively, and the glass transition temperature increased from 70 to $76^{\circ} \mathrm{C}$.

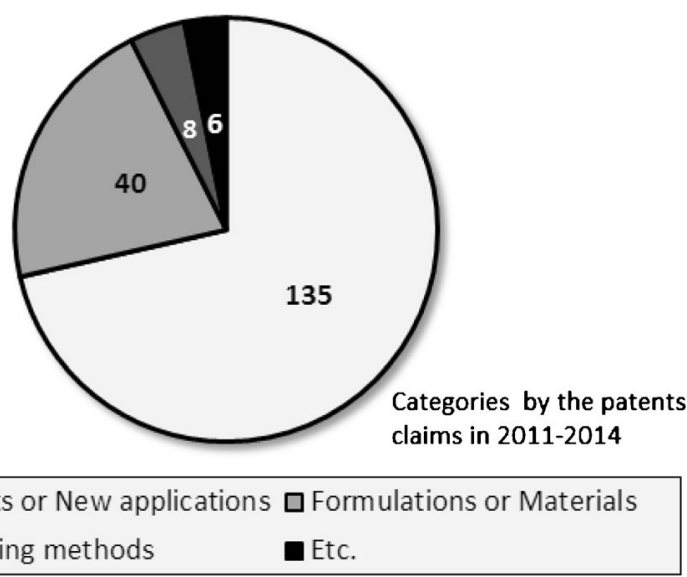

Fig. 4 The patent numbers in 2011 to 2014 categorized by their claims

A critical issue in utilizing cellulose nanoparticles on the industrial scale centers on using continuous processing methods such as extrusion. However, the filler content is unable to exceed $15 \mathrm{vol} \%$ during extrusion for the sake of aggregation and degradation [90•]. A percentage below $30 \mathrm{vol} \%$ is not enough for cellulose nanoparticles to form hydrogenbonded percolating network that leads to high-performance cellulose nanocomposites [90•]. Future research should address the issue of cellulose nanoparticle loading in polymers.

Applications for cellulose nanocomposites are various such as structural materials, biomedical scaffolds, optical devices, barrier films, battery components, coatings, automobile parts, etc. For further information, please refer to other review articles on cellulose nanomaterials [91-93].

\section{WPC Patent Activity}

Over 500 patents containing the phrase "wood-plastic composites" have been registered to US patent office since
Fig. 3 Total number of US patents related to wood-plastic composites since 1950

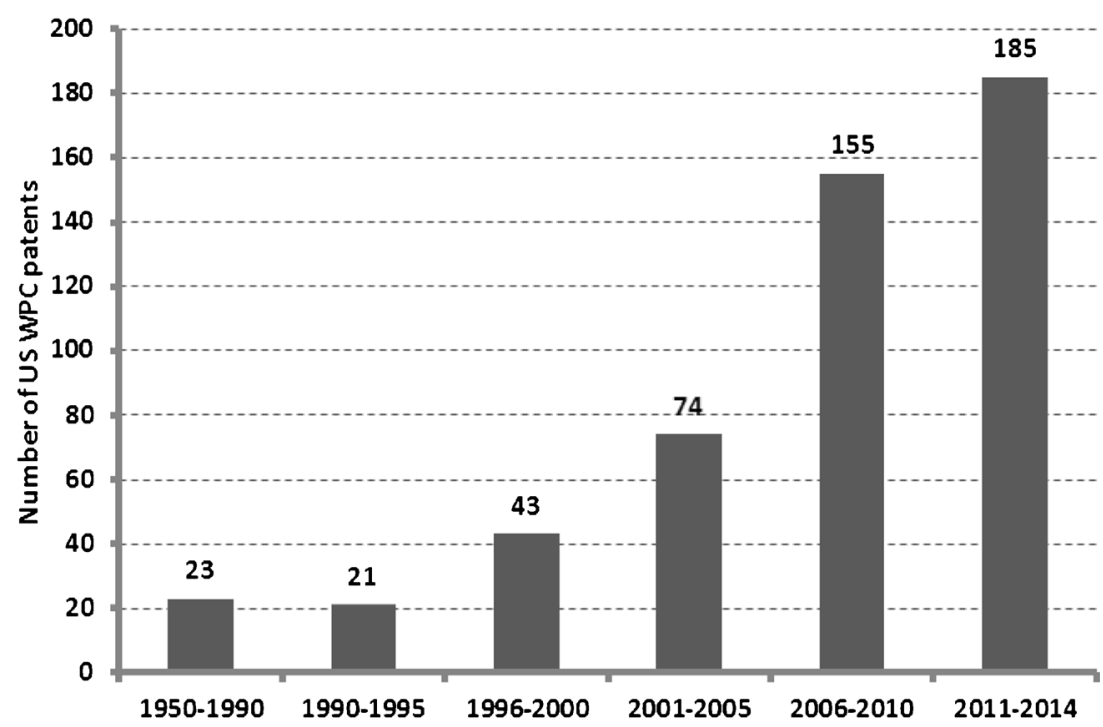


1950. The numbers of new patent registrations are chronologically shown in Fig. 3. The patent registrations have continued to increase up to 2015 . The 1990 s patents mainly dealt with formulations of materials of wood components, such as fibers, flour, and wood chips, with a variety of conventional polymers. The matrix polymers are now majorly polyolefin plastics in the USA because of their superior properties for outdoor applications. Another major trend of the patents applications in the 1990s was to develop better processing methods for improved production rates and distribution and dispersion of wood components into polymer matrices. After the WPC market leveled off and matured by successful major products (decking boards and rails) in the 2000 s, the trend of patent registrations has shifted to new products or applications instead of the materials itself. The expansion of WPC markets into different industries implies that the current and existing construction markets have matured with a low annual growth rate. Otherwise, minor or middle-sized WPC manufacturers are weakening because of the severe competition with a few major manufacturing players.

Since 2011, the claims of the registered patents have been focused on WPC parts utilized in non-building applications, such as water treatment equipment (US 8,501,016) [94], packaging structures (US 6,541,097) [95], and even photovoltaics (US 8,307,606) [96] modules. The percentage of the patents by claimed categories is displayed in Fig. 4 .

\section{Conclusions}

Wood-plastic composite technology continues to mature with improvements being made in manufacturing processes (extrusion, injection, and compression molding); material advances in novel polymers matrices, treatments, and additives; profiles and parts for construction, automobiles, and furniture; durability from weather, fire, and biological attack; as well as the development of product standards for building construction. New developments are being made especially in the area of nano additives for WPCs including nanocellulose. Patent activity in WPCs continues to increase with the development of new product types and market application areas.

\section{Compliance with Ethics Guidelines}

Conflict of Interest Dr. Gardner has a patent 7,659,330 issued, and a patent 8,221,663 issued.

Dr. Han has a patent 7,659,330 issued, and a patent 8,221,663 issued. Dr. Wang has no conflicts to declare.

Human and Animal Rights and Informed Consent This article contains no studies with human or animal subjects performed by the authors.

\section{References}

Papers of particular interest, published recently, have been highlighted as:

- Of importance

1. Forest Products Laboratory. Wood handbook-wood as an engineering material. General Technical Report FPL-GTR-190. Madison: Department of Agriculture, Forest Service, Forest Products Laboratory; 2010. p. 508.

2. Gordon JE. The new science of strong materials (or why you don't fall through the floor). Princeton: Princeton University Press; 1988. p. 179.

3. Rowell RM, Konkol P. Treatments that enhance physical properties of wood. Gen. tech. rep. FPL-GTR-55. Madison: Department of Agriculture, Forest Service, Forest Products Laboratory; 1987. p. 12.

4. Simonds HR, Weith AJ, Schack W. Extrusion of plastics, rubber, and metals. New York: Reinhold Publishing; 1952. p. 454.

5. Oksman Niska K, Sain M. Wood-polymer composites. Cambridge: Woodhead Publishing, Ltd; 2008. p. 384.

6. Klyosov AA. Wood-plastic composites. John Wiley \& Sons; 2007; $702 p$.

7. Bogoeva-Gaceva G, Avella M, Malinconico M, Buzarovska A, Grozdanov A, Gentile G, et al. Natural fiber eco-composites. Polym Compos. 2007;28(1):98-107.

8. Gephardt A. Understanding additive manufacturing. Cincinnati: Hanser Publications; 2012. p. 164.

9. Ibrahim M, Badrishah N, Sa'ude N, Ibrahim MHI. Sustainable natural bio composite for FDM feedstocks. Appl Mech Mater. 2014;607:65-9.

10. Wendel B, Rietzel D, Kühnlein F, Feulner R, Hülder G, Schmachtenberg E. Additive processing of polymers. Macromol Mater Eng. 2008;293(10):799-809.

11. Jiang K, Guo Y, Bourell DL. Study on the microstructure and binding mechanisms of selective laser sintered wood plastic composite. 2013. http://sffsymposium.engr.utexas.edu/Manuscripts/2013/2013-39Jiang.pdf. Accessed 31 May 2015.

12. Kuo PY, Wang SY, Chen JH, Hsueh HC, Tsai MJ. Effects of material compositions on the mechanical properties of wood-plastic composites manufactured by injection molding. Mater Des. 2009;30(9):3489-96.

13. Gosselin R, Rodrigue D, Riedl B. Injection molding of postconsumer wood-plastic composites I: morphology. J Thermoplast Compos Mater. 2006;19(6):639-57.

14. Gosselin R, Rodrigue D, Riedl B. Injection molding of postconsumer wood-plastic composites II: mechanical properties. J Thermoplast Compos Mater. 2006;19(6):659-69.

15. Sykacek E, Hrabalova M, Frech H, Mundigler N. Extrusion of five biopolymers reinforced with increasing wood flour concentration on a production machine, injection moulding and mechanical performance. Compos A: Appl Sci Manuf. 2009;40(8):1272-82.

16. Holbery J, Houston D. Natural-fiber-reinforced polymer composites in automotive applications. JOM. 2006;58(11):80-6.

17. Gardner, DJ, Y Han. Towards structural wood plastic composites: technical innovations. In: Proceedings of the 6th Annual Meeting of the Nordic-Baltic Network in Wood Material Science and Engineering, October 21-22, Tallinn, Estonia; 2010. p. 7-22.

18. Gardner DJ, Han Y, West CH. FRP-reinforced wood-plastic composite panels for structural applications. Madison: 11th International Conference on Wood \& Biofiber Plastic Composites; 2011.

19. Adhikary KB, Pang SS, Staiger MP. Dimensional stability and mechanical behaviour of wood-plastic composites based on recycled 
and virgin high-density polyethylene (HDPE). Compos Part B. 2008;39(5):807-15.

20. Espert A, Vilaplana F, Karlsson S. Comparison of water absorption in natural cellulosic fibres from wood and one-year crops in polypropylene composites and its influence on their mechanical properties. Compos A Appl Sci Manuf. 2004;35(11):1267-76.

21. Jiang HH, Kamdem DP. Development of poly(vinyl chloride)/ wood composites. A literature review. J Vinyl Addit Technol. 2004;10(2):59-69.

22. Poletto M, Dettenborn J, Zeni M, Zattera AJ. Characterization of composites based on expanded polystyrene wastes and wood flour. Waste Manag. 2011;31(4):779-84.

23. Kumar B, Zaidi MGH, Rathore S, Rai AK, Thakur IS, Sah PL. Optical, morphological, thermal, mechanical, and fungal characterization of wood polymethyl methacrylate composites. Instrum Sci Technol. 2006;34(1-2):67-83.

24. Chen JM, Gardner DJ. Dynamic mechanical properties of extruded nylon-wood composites. Polym Compos. 2008;29(4):372-9.

25. Lei $\mathrm{Y}, \mathrm{Wu} \mathrm{QW}$. Wood plastic composites based on microfibrillar blends of high density polyethylene/poly(ethylene terephthalate). Bioresour Technol. 2010;101(10):3665-71.

26. Mahfoudh A, Cloutier A, Rodrigue D. Characterization of UHMWPE/wood composites produced via dry-blending and compression molding. Polym Compos. 2013;34(4):510-6.

27. Chotirat L, Chaochancbaikul K, Sombatsompop N. On adhesion mechanisms and interfacial strength in acrylonitrile-butadiene-styrene/wood sawdust composites. Int J Adhes Adhes. 2007;27(8): 669-78.

28. Simonsen J, Jacobsen R, Rowell R. Wood-fiber reinforcement of styrene-maleic anhydride copolymers. J Appl Polym Sci. 1998;68(10):1567-73.

29. Han Y, Gardner D. Foamed styrene-based WPC using physical blowing agent created during reactive extrusion. 10th International Conference on Wood and Bio fiber Plastic Composites and Cellulose Nanocomposites Symposium. May; 2010. Proceedings No. 7218-09, Forest Products Society, Madison, WI pp. 27-35. Reactive extrusion to create foamed WPCs.

30. Gregorova A, Hrabalova M, Wimmer R, Saake B, Altaner C. Poly (lactide acid) composites reinforced with fibers obtained from different tissue types of Picea sitchensis. J Appl Polym Sci. 2009;114(5):2616-23.

31. Shah BL, Selke SE, Walters MB, Heiden PA. Effects of wood flour and chitosan on mechanical, chemical, and thermal properties of polylactide. Polym Compos. 2008;29(6):655-63.

32. Lee SH, Ohkita T. Mechanical and thermal flow properties of wood flour-biodegradable polymer composites. J Appl Polym Sci. 2003;90(7):1900-5.

33. RÂPĂ M, Popa ME, CORNEA PC, Ioan V, POPA EG, Geicu-Cristea $M$, et al. Degradation study by trichoderma spp. of poly (3-hydroxybuthyrate) and wood fibers composites. Rom Biotechnol Lett. 2014;19(3):9390-9.

34. Singh S, Mohanty A. Wood fiber reinforced bacterial bioplastic composites: fabrication and performance evaluation. Compos Sci Technol. 2007;67(9):1753-63.

35. Pelaez-Samaniego MR, Yadama V, Lowell E, Espinoza-Herrera R. A review of wood thermal pretreatments to improve wood composite properties. Wood Sci Technol. 2013;47(6):1285-319.

36. Andrusyk L, Oporto GS, Gardner DJ, Neivandt DJ. Wood plastic composites manufactured from hot water extracted wood. Part I: mechanical evaluation. Proceedings of the 51st international convention of society of wood science and technology, November; 2008.

37. Hosseinaei O, Wang S, Enayati AA, Rials TG. Effects of hemicellulose extraction on properties of wood flour and wood-plastic composites. Compos A: Appl Sci Manuf. 2012;43(4):686-94.
38. Pelaez-Samaniego MR, Yadama V, Lowell E, Amidon TE, Chaffee TL. Hot water extracted wood fiber for production of wood plastic composites (WPCs). Holzforschung. 2013;67(2):193-200.

39. Kim BS, Chun BH, Lee WI, Hwang BS. Effect of plasma treatment on the wood flour for wood flour/PP composites. J Thermoplast Compos Mater. 2009;22(1):21-8.

40. Dong S, Sapieha S, Schreiber HP. Mechanical properties of coronamodified cellulose/polyethylene composites. Polym Eng Sci. 1993;33(6):343-6.

41. Li X, Tabil LG, Panigrahi S. Chemical treatments of natural fiber for use in natural fiber-reinforced composites: a review. J Polym Environ. 2007;15(1):25-33.

42. $\mathrm{Lu} \mathrm{JZ,} \mathrm{Wu} \mathrm{Q,} \mathrm{McNabb} \mathrm{HS.} \mathrm{Chemical} \mathrm{coupling} \mathrm{in} \mathrm{wood} \mathrm{fiber} \mathrm{and}$ polymer composites: a review of coupling agents and treatments. Wood Fiber Sci. 2000;32(1):88-104.

43. Dányádi L, Janecska T, Szabó Z, Nagy G, Móczó J, Pukánszky B. Wood flour filled PP composites: compatibilization and adhesion. Compos Sci Technol. 2007;67(13):2838-46.

44. Bengtsson M, Oksman K. Silane crosslinked wood plastic composites: processing and properties. Compos Sci Technol. 2006;66(13): 2177-86.

45. Dányádi L, Móczó J, Pukánszky B. Effect of various surface modifications of wood flour on the properties of $\mathrm{PP} /$ wood composites. Compos A: Appl Sci Manuf. 2010;41(2):199-206.

46. Ichazo M, Albano C, Gonzalez J, Perera R, Candal M. Polypropylene/ wood flour composites: treatments and properties. Compos Struct. 2001;54(2):207-14.

47. Mbarek TB, Robert L, Sammouda H, Charrier B, Orteu JJ, Hugot F. Effect of acetylation and additive on the tensile properties of wood fiber-high-density polyethylene composite. J Reinf Plast Compos. 2013;32(21):1646-55.

48. Wei LQ, McDonald AG, Freitag C, Morrell JJ. Effects of wood fiber esterification on properties, weatherability and biodurability of wood plastic composites. J Polym Degrad Stab. 2013;98: 1348-61.

49. Adhikary KB, Park CB, Islam M, Rizvi GM. Effects of lubricant content on extrusion processing and mechanical properties of wood flour-high-density polyethylene composites. J Thermoplast Compos Mater. 2011;24(2):155-71.

50. Li T, Wolcott M. Rheology of wood plastics melt, part 2: effects of lubricating systems in HDPE/maple composites. Polym Eng Sci. 2006;46(4):464-73.

51. Simonsen J, Freitag CM, Silva A, Morrell JJ. Wood/plastic ratio: effect on performance of borate biocides against a brown rot fungus. Holzforschung. 2005;58(2):205-8.

52. Dawson-Andoh B, Matuana L. High density polyethylene-wood flour composite lumber: efficacy of two proprietary biocides in the control of fungal colonization and discoloration. Holz Roh Werkst. 2007;65(5):331-4.

53. Muasher M, Sain M. The efficacy of photo stabilizers on the color change of wood filled plastic composites. Polym Degrad Stab. 2006;91(5):1156-65.

54. Chaochanchaikul K, Sombatsompop N. Stabilizations of molecular structures and mechanical properties of PVC and wood/PVC composites by Tinuvin and $\mathrm{TiO} 2$ stabilizers. Polym Eng Sci. 2011;51(7):1354-65.

55. Chaochanchaikul K, Rosarpitak V, Sombatsompop N. Structural and thermal stabilizations of PVC and wood/PVC composites by metal stearates and organotin. Bioresources. 2011;6(3):3115-31.

56. Geng Y, Li K, Simonsen J. Effects of a new compatibilizer system on the flexural properties of wood-polyethylene composites. J Appl Polym Sci. 2004;91(6):3667-72.

57. Geng Y, Li K, Simonsen J. A combination of poly(diphenylmethane diisocyanate) and stearic anhydride as a novel compatibilizer for wood-polyethylene composites. J Adhes Sci Technol. 2005;19(11): 987-1001. 
58. Faruk O, Bledzki AK, Matuana LM. Microcellular foamed woodplastic composites by different processes: a review. Macromol Mater Eng. 2007;292(2):113-27.

59. Bledzki AK, Faruk O. Effects of the chemical foaming agents, injection parameters, and melt-flow index on the microstructure and mechanical properties of microcellular injection-molded woodfiber/polypropylene composites. J Appl Polym Sci. 2005;97(3): 1090-6.

60. Zhang H, Rizvi GM, Park CB. Development of an extrusion system for producing fine-celled HDPE/wood-fiber composite foams using $\mathrm{CO}_{2}$ as a blowing agent. Adv Polym Technol. 2004;23(4):263-76.

61. Bledzki A, Faruk O. Microcellular wood fibre reinforced PP composites: a comparative study between extrusion, injection moulding and compression moulding. Int Polym Process. 2006;21(3):256-62.

62. Stark NM, White RH, Mueller SA, Osswald TA. Evaluation of various fire retardants for use in wood flour-polyethylene composites. Polym Degrad Stab. 2010;95(9):1903-10. Use of fire retardant additives in WPCs.

63. Qiang T, Yu D, Gao H. Wood flour/polylactide biocomposites toughened with polyhydroxyalkanoates. J Appl Polym Sci. 2012;124(3):1831-9.

64. Qiang T, Yu D, Gao H, Wang Y. Polylactide-based wood plastic composites toughened with SBS. Polym Plast Technol Eng. 2012;51(2):193-8. Use of biobased polymer matrix for WPCs.

65. Marathe DS, Joshi PS. Characterization of highly filled wood flourPVC composites: morphological and thermal studies. J Appl Polym Sci. 2009;114(1):90-6.

66. Xie Z, Jin L. Effect of plasticizer on the properties of acetylated wood flour/LDPE composites. Futur Energy, Environ Mater. 2014;88:229-35.

67. Stark NM, Gardner DJ. Outdoor durability of wood-polymer composites. In: Oksman Niska K, Sain M, editors. Wood polymer composites. Cambridge: Woodhead Publishing Limited; 2008. p. 142-65.

68. Morrell JJ, Stark NM, Pendleton DE, McDonald AG. Durability of wood-plastic composites. 10th International Conference on Wood \& Biofiber Plastic Composites and Cellulose Nanocomposites Symposium. Madison: Forest Products Society; 2010. ISBN 9781-892529-55-8.

69. Lauzon M. Trex wins court approval to settle class action lawsuit. In: Plastics news. August 22, 2013. http://www.plasticsnews.com/ article/20130822/NEWS/130829967/trex-wins-court-approval-tosettle-class-action-lawsuit\&template $=$ printthis

70. Ashori A, Matini Behzad H, Tarmian A. Effects of chemical preservative treatments on durability of wood flour/HDPE composites. Compos Part B. 2013;47:308-13.

71. Schirp A, Wolcott MP. Influence of fungal decay and moisture absorption on mechanical properties of extruded wood-plastic composites. Wood Fiber Sci. 2005;37(4):643-52.

72. Fabiyi JS, McDonald AG. Effect of wood species on property and weathering performance of wood plastic composites. Compos A: Appl Sci Manuf. 2010;41(10):1434-40.

73. Fabiyi JS, McDonald AG, Morrell JJ, Freitag C. Effects of wood species durability and chemical changes on fungal decayed wood plastic composites. Compos A Appl Sci Manuf. 2011;42(5): 501-10.

74. Kim JW, Harper DP, Taylor AM. Effect of wood species on water sorption and durability of wood-plastic composites. Wood Fiber Sci. 2008;40(4):519-31.

75. Stark NM, Matuana LM. Characterization of weathered woodplastic composite surfaces using FTIR spectroscopy, contact angle, and XPS. Polym Degrad Stab. 2007;92(10):1883-90.
76. Fabiyi JS, McDonald AG, Wolcott MP, Griffiths PR. Wood plastic composites weathering: visual appearance and chemical changes. Polym Degrad Stab. 2008;93(8):1405-14.

77. Stark NM, Matuana LM. Coating WPCs using co-extrusion to improve durability. Proceedings of coating wood and wood composites: designing for durability. Seattle; 2007. P. 23-25.

78. Ayrilmis N, Jarusombuti S, Fueangvivat V, Bauchongkol P. Effect of thermal-treatment of wood fibres on properties of flat-pressed wood plastic composites. Polym Degrad Stab. 2011;96(5):818-22.

79. Segerholm BK, Ibach RE, Wålinder ME. Moisture sorption in artificially aged wood-plastic composites. Bioresources. 2012;7(1): 1283-93.

80. Garcia M, Hidalgo J, Garmendia I, García-Jaca J. Wood-plastics composites with better fire retardancy and durability performance. Compos A: Appl Sci Manuf. 2009;40(11):1772-6.

81. Stark NM, Mueller SA, White RH, Osswald TA. Effect of fire retardants on heat release rate of wood flour-polyethylene composites. 10th International Conference on Wood \& Biofiber Plastic Composite and Cellulose Nanocomposites Symposium; 2009: p. 103-109.

82. Mariano M, El Kissi N, Dufresne A. Cellulose nanocrystals and related nanocomposites: review of some properties and challenges. J Polym Sci B Polym Phys. 2014;52(12):791-806.

83. Siró I, Plackett D. Microfibrillated cellulose and new nanocomposite materials: a review. Cellulose. 2010;17(3):459-94.

84. Xu X, Liu F, Jiang L, Zhu J, Haagenson D, Wiesenborn DP. Cellulose nanocrystals vs. cellulose nanofibrils: a comparative study on their microstructures and effects as polymer reinforcing agents. ACS Appl Mater Interfaces. 2013;5(8):2999-3009.

85. Malainine ME, Mahrouz M, Dufresne A. Thermoplastic nanocomposites based on cellulose microfibrils from Opuntia ficus-indica parenchyma cell. Compos Sci Technol. 2005;65(10):1520-6.

86. Leitner J, Hinterstoisser B, Wastyn M, Keckes J, Gindl W. Sugar beet cellulose nanofibril-reinforced composites. Cellulose. 2007;14(5): 419-25.

87. Alemdar A, Sain M. Biocomposites from wheat straw nanofibers: morphology, thermal and mechanical properties. Compos Sci Technol. 2008;68(2):557-65.

88. Peng Y, Gallegos SA, Gardner DJ, Han Y, Cai Z. Maleic anhydride polypropylene modified cellulose nanofibril polypropylene nanocomposites with enhanced impact strength. Polym Compos. 2014. doi:10.1002/pc.23235.

89. Jonoobi M, Harun J, Mathew AP, Oksman K. Mechanical properties of cellulose nanofiber (CNF) reinforced polylactic acid (PLA) prepared by twin screw extrusion. Compos Sci Technol. 2010;70(12): $1742-7$.

90. Lee KY, Aitomäki Y, Berglund LA, Oksman K, Bismarck A. On the use of nanocellulose as reinforcement in polymer matrix composites. Compos Sci Technol. 2014;105:15-27. Use of nanocellulose in polymer matrix composites.

91. Hubbe MA, Rojas OJ, Lucia LA, Sain M. Cellulosic nanocomposites: a review. Bioresources. 2008;3(3):929-80.

92. Siqueira G, Bras J, Dufresne A. Cellulosic bionanocomposites: a review of preparation, properties and applications. Polymers. 2010;2(4):728-65.

93. Lin N, Huang J, Dufresne A. Preparation, properties and applications of polysaccharide nanocrystals in advanced functional nanomaterials: a review. Nanoscale. 2012;4(11):3274-94.

94. Lord CA, Tracy SP, Zwonitzer NS. Storm water pretreatment chamber. U.S. Patent 8,501,016, 2013.

95. Lynch SK, Liang BH, Frein F, Luetgert KA, Farrell DJ. Ribbed board. U.S. Patent 6,541,097, 2003.

96. Rego D, Rodowca JQ, Striner BM, Rethans JW. Integrated photovoltaic rooftop modules. U.S. Patent 8,307,606, 2012. 